\title{
Faculty Perceptions of the Factors Influencing Success in STEM fields
}

\author{
Eshani Gandhi-Lee ${ }^{1}$, Heather Skaza, Erica Marti, PG Schrader, MaryKay Orgill \\ University of Nevada, Las Vegas, USA
}

\begin{abstract}
The recent decline in the number of graduates in the fields of Science, Technology, Engineering and Mathematics (STEM) has significant implications for the nation's economic and societal well-being (PCAST, 2012). Because university faculty members' interactions with students - both in and out of the classroom - have a significant impact on student recruitment and retention and because faculty beliefs have a significant impact on faculty practices (Astin \& Astin, 1992), we have interviewed university faculty members in order to examine their perceptions of successful STEM students. Here, we report faculty members' perceptions of the characteristics of successful tertiary STEM students, as well as their perceptions of the major obstacle to student success in STEM courses and programs of study. While faculty perceptions of the characteristics of successful STEM students generally align with the research literature, faculty did not mention experiences or instructional strategies they could implement in their classrooms to help students develop these characteristics. The results of the current study could inform the design of faculty professional development to ensure that faculty are aware of the various ways they can support student success in STEM fields.
\end{abstract}

Keywords: STEM pipeline, Recruitment \& Retention, Perceptions, Faculty, Student characteristics

The economic and societal progress of the U.S. relies on producing innovative minds to meet the developmental demands of tomorrow. As such, the more recent decline in graduates in the fields of science, technology, engineering, and mathematics (STEM) has significant implications for the nation's economic and societal well-being (Ashby, 2006; Commission on Professionals in Science and Technology [CPST], 2007; Hall et al., 2011; Lowell \& Regets, 2006). In his 2012 State of the Union address, President Obama reported that there were twice as many job openings in STEM fields as there were workers to fill those jobs (State of the Union, 2012). According to the 2012 report of the President's Council of Advisors on Science and Technology (PCAST, 2012), the U.S. must increase STEM degree graduates by $34 \%$ annually in order to produce the approximately 1 million more STEM professionals needed over the next decade. These circumstances call for a national prioritization of STEM education, as well as a systemic evaluation of the factors impacting recruitment and retention in STEM education.

Our interest is the recruitment and retention of undergraduate STEM students. Research indicates that there is significant attrition among STEM majors (Rask, 2010; Seymour \& Hewitt, 1994; Tobias, 1990). Studies have examined the factors that promote student recruitment and retention in STEM courses and programs of study (Astin \& Astin, 1992; Chang et al., 2014; Hall et al., 2011). These studies have found that faculty play an instrumental role in how students understand and experience STEM fields, especially in the early years of college (Astin \& Astin, 1992; Kuh \& Hu, 2001; Newman, 2011; Rask, 2010), the most important for recruitment and retention of STEM majors (PCAST, 2012).

${ }^{1}$ Corresponding author. College of Sciences, Department of Chemistry \& Biochemistry, University of Nevada, Las Vegas, 4505 S. Maryland Parkway, Mail Stop 4003, Las Vegas, NV 89154-4003. Email: MaryKay.Orgill@unlv.edu

Gandhi-Lee, E., Skaza, H., Marti, E., Schrader, P.G., \& Orgill, M. (2015). Faculty perceptions of the factors influencing success in STEM fields. Journal of Research in STEM Education, 1(1), 30-44. 
Faculty beliefs about their students and their students' abilities ultimately influence what happens in STEM classrooms (Fang, 1996; Kember, 1997; Nespor, 1987; Pajares, 1992), and what happens in STEM classrooms influences the recruitment and retention of STEM majors (Maltese and Tai, 2011; Watkins \& Mazur, 2013). Despite this fact, very little research has examined university STEM faculty perceptions of the characteristics of successful STEM students or of the roadblocks to STEM students' success. With the current study, we attempt to address this gap in the literature.

\section{Review of Relevant Literature}

Previous research has examined the correlation between specific student characteristics and experiences and the likelihood that students choose STEM majors and persist in STEM fields. In order to situate university STEM faculty perceptions of the characteristics of successful tertiary STEM students, we first review this literature, identifying factors that are known to contribute to recruitment and retention in tertiary STEM programs of study. We will discuss factors that fall into four major themes: characteristics that are internal to the student; student interactions with faculty; student interactions with peers; and, finally, classroom environment.

In addition, because the current study involves an examination of faculty perceptions of their students, and because these perceptions influence what instructors do in their classrooms, we briefly review the literature about the connection between teacher beliefs and classroom practice.

\section{Factors Affecting Undergraduate STEM Retention}

Characteristics Internal to the Student. Some of the factors that are known to correlate with students' choice of or persistence in a STEM field are internal or characteristics of the students themselves. The most common of these is students' orientation toward math. This orientation has two components. First, mastery of math content is a predictor of student success in undergraduate STEM courses and programs of study (Astin \& Astin, 1992). Perhaps more significantly, students with high math self-efficacy were more likely to choose a science major in college (Astin \& Astin, 1992; Betz \& Hackett, 1983).

In addition to strong abilities and self-efficacy in math, student intention and interest in STEM are strong predictors of their persistence to graduation in STEM disciplines. Sullins et al.'s 1995 study found that student interest in biology was directly related to their intention to major in biology. Astin and Astin (1992) found that student intentions to major in STEM fields as freshmen were the strongest predictor for those who completed degrees in science and engineering.

Student interactions with faculty. Previous research reports the influence of certain external factors on student retention in STEM programs of study. A significant factor that is particularly relevant to the current study is the role that faculty members play in the persistence of undergraduates in STEM fields. Studies have found that faculty can impact student interest in, performance in, and attitudes about STEM disciplines in a number of ways, both positive and negative. Sullins et al. (1995) describe general student/faculty contact as being beneficial to students' persistence in STEM. Other studies go further to address three specific types of faculty interactions with students that can contribute to student persistence in STEM courses and programs of study: interactions in the classroom, interactions in which the faculty member acts as a research advisor for the student, and interactions in which the faculty member acts as a mentor for the student.

At the tertiary level, daily classroom teaching practices can have a significant effect on whether students persist in STEM courses and programs of study. Watkins and Mazur (2013) suggest that a single positive experience-even one as simple as an instructor's demonstrating enthusiasm for teaching the course-could have a significant long-term impact on a student's decision to persist in STEM disciplines. Conversely, student-perceived poor classroom teaching is often given as a reason for students leaving science, ranking just behind loss of interest in science and growing interest in another field (Seymour \& Hewitt, 1997). 
Maltese and Tai (2011) described ways in which faculty affected student persistence in science through their classroom practices. Some important faculty practices inside the classroom were (1) teacher enthusiasm for the subject matter, (2) contextualizing content in subject matter important to students, (3) stimulating lessons, and (4) discussion about careers and issues in science. Active teaching methods such as these afford the instructor a greater opportunity to listen and interact with students than do more traditional, didactic methods (Watkins \& Mazur, 2013).

Outside of the classroom, faculty members can have direct impact on STEM student retention by engaging students in undergraduate research (Astin \& Astin, 1992). Undergraduate research programs foster positive relationships between students and faculty (Bounous-Hammarth, 2000) that lead students to view faculty as mentors, rather than simply as instructors (Astin \& Astin, 1992). The relationships developed through undergraduate research retain students in STEM disciplines and, in fact, increase the likelihood that students will pursue graduate school (Thiry, Laursen, \& Hunter, 2011).

Even if STEM faculty do not act in the formal role of research advisors to undergraduate students, they are still positioned to be meaningful mentors to novice students. These more informal mentoring relationships can lead to students' persistence in STEM fields as well. As mentors, faculty can effectively advise students about their coursework and program of study (Bounous-Hammarth, 2000); they can set high expectations for students' success and demonstrate a high level of concern for individual students (Sullins et al., 1995); and they can exhibit and help students develop an enthusiasm for the field (Walden \& Foor, 2008).

Interactions with peers. Interactions between instructor and student are not the only influential relationships a student experiences during their program of study. Previous research has found peer relationships to be important to the selection of and persistence in STEM disciplines. Students' academic interactions, which might include interactions with their peers, instructors, or academic advisors, help align their academic aspirations with their choices (Wang, 2013). For example, Astin and Astin (1992) found that students were more likely to graduate in the physical sciences if their peers also chose a physical science major. Graduation was also more likely for physical science students who tutored or peer-taught other students. Watkins and Mazur (2013) studied peer-to-peer instruction in the physics classroom. They found that students who were taught in traditional instruction classrooms, focused on faculty-to-student instruction, were more than twice as likely to transfer out of a STEM major than students who participated in the peer instruction classrooms.

Classroom environment. The STEM classroom environment has also been shown to have an impact on students' likelihood to major in STEM. In the classroom, Maltese and Tai (2011) found that undergraduates who enjoyed an introductory science course were more likely to major in a STEM discipline. Sullins et al. (1995) described more specific characteristics of a successful STEM classroom environment. These programs had small class sizes, a low student-to-faculty ratio, a high level of cooperation among students, and an emphasis on research.

Relevance to current study. The importance of this discussion of factors influencing persistence of tertiary students in STEM courses and programs of study is apparent when considering the potential role of faculty in the experiences of students in STEM disciplines. Engaged faculty members have the ability to directly impact students through their interactions in and out of the classroom. In the classroom, faculty can show enthusiasm for their field, demonstrate concern for students both individually and as a group, promote peer-to-peer interactions through in-class group work, and cultivate interest in the field through the teaching practices they choose to implement. Outside of the classroom, an undergraduate research program provides the opportunity for faculty to interact with students as mentors, enable peer-to-peer collaboration, and facilitate students working as STEM professionals on meaningful research programs.

It is clear from the preceding discussion that faculty have the potential to positively influence students' persistence in tertiary STEM courses and programs of study, based on how they interact with their students. Current research suggests that the ways faculty choose to interact with their students are influenced, at least in part, by their beliefs about teaching, learning, their students, and the context in which they teach. 


\section{The Impact of Faculty Beliefs on Classroom Practice}

A number of studies have indicated that the beliefs of K-12 teachers play a major role in their decision-making about curricula and the instructional strategies they employ in their classrooms (see, for example, Fang, 1996; Kember, 1997; Nespor, 1987). In fact, Pajares (1992), who reviewed the literature about K-12 teachers' beliefs, stated that beliefs are the "best indicators of the decisions that individuals make throughout their lives" and that "few would argue that the beliefs teachers hold influence their perceptions and judgments, which, in turn, affect their behavior in the classroom" (p. 307). The research about university academics' beliefs, although more limited than that about K-12 teachers, shows a similar trend: beliefs influence practice (see, for example, Brown et al., 2006; Fang, 1996; Kember, 1997; Sunal et al., 2001).

Teachers' beliefs about teaching and learning and their perceptions of the abilities of their students affect what actually happens in the classroom (Brown et al., 2006; Johnson \& Hall, 2007; Laplante, 1997). According to Johnson and Hall (2007),

In addition to the beliefs teachers hold about teaching and learning are their perceptions of the students they teach. Both teacher beliefs about learning and perceptions about their students translate into classroom instructional practice. These practices in turn, shape the dynamics of student learning. (p. 1)

These two belief sets are often at odds with each other. For example, an instructor might believe that, in general, students learn STEM content best as they participate in student-focused, inquiry-based activities that require them to find and explain patterns in raw data. Despite having this belief, if the instructor also believes that the particular students in his classroom do not possess the mathematical and critical thinking skills necessary to make sense of data, he may resort to more teacher-focused, didactic approaches in the classroom. The teaching strategies employed in a classroom, then, result from a negotiation between an instructors' idealized beliefs about teaching and learning and their perceptions of their students' abilities and other context-based factors, such as a need to cover a large amount of information in a limited amount of time or the culture and expectations of their schools and departments (Brown et al., 2006; Fang, 1996; Mansour, 2009; Sunal et al., 2001).

\section{Purpose of the Current Study}

The purpose of the current study is to examine the perceptions university STEM faculty have of their students. There are two reasons we considered this an important population for examination. First, university STEM faculty are the "experts at the end" of a STEM educational experience. As such, STEM faculty should have a valuable perspective on the characteristics of successful STEM students. An understanding of those characteristics could inform the development of learning experiences in primary and secondary education. Second, in many cases, university faculty could be seen as the final "gatekeepers" of STEM pathways (Venville et al., 2013). In order for students to progress toward STEM-related careers, they often have to successfully negotiate the courses and programs run by these faculty members. Indeed, research shows that faculty can have both positive and negative influences on students' recruitment and retention into STEM-related fields and careers. For example, positive student/faculty interactions are cited as a major factor related to students' decisions to remain in STEM-related majors (see the discussion in the previous section). On the other hand, several studies have indicated that poor teaching in introductory STEM courses may be driving off students who would otherwise be interested in STEM-related careers (Lichtenstein et al., 2007; Seymour \& Hewitt, 1994; Sunal et al., 2001; Tobias, 1990). Given that faculty beliefs about students influence how they interact with students and the methods they choose to employ in their courses, it also is important to examine faculty beliefs about the abilities of their current students.

We developed the following research questions to guide our examination of university faculty members' perceptions of successful STEM students. 
1. What are faculty perceptions of the characteristics of successful STEM students?

2. What are faculty perceptions of the major barriers to students' success in STEM courses and programs of study?

\title{
Methodology
}

We chose to use phenomenography as the theoretical framework for this study. Phenomenography is an empirical research tradition that was designed to answer questions about thinking and learning, especially in the context of educational research (Marton, 1986; Orgill, 2007). Its objective is to define the different ways in which people experience, interpret, understand, perceive, or conceptualize a phenomenon or certain aspect of reality.

In order to determine how university STEM faculty perceive their students and their students' abilities, we interviewed 27 STEM faculty, representing multiple disciplinary areas, at a Southwestern research university (Figure 1). As participation in the current study was voluntary, the distribution of faculty members interviewed is not representative of the university. All interviews were semi-structured and conversational in style, lasting approximately 30-45 minutes each. We began each interview by asking faculty to tell us about their educational background, the type of research they do, and the classes they typically teach. We continued by asking faculty about the preparedness of students for the classes they teach. Then we asked faculty to define the desirable characteristics, skills, and knowledge base of students who are successful in their fields and how they thought students could develop those skills. The major focus of the current manuscript will be on the faculty members' perceptions of the characteristics of their successful STEM students, although we will comment briefly in the Discussion section about how faculty members perceive that students can develop these characteristics.

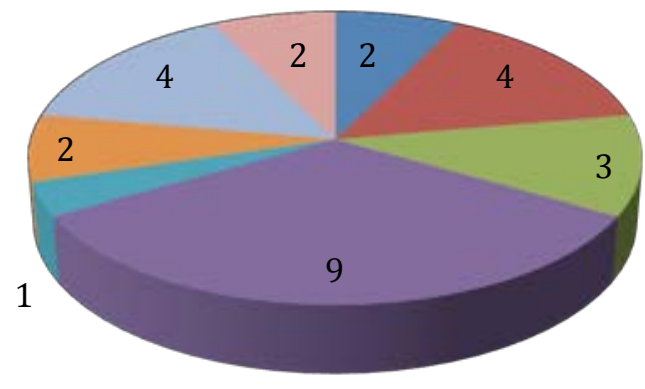

\author{
घiology \\ - Chemistry \\ - Computer Science \\ Engineering \\ - Geoscience \\ - Health Sciences \\ Mathematics \\ Physics
}

Figure 1. Distribution of faculty participants by STEM-related discipline.

We transcribed each of the interviews verbatim. Based on an initial reading of the transcripts and their knowledge of the literature, three authors (EG, HS, and MO) identified themes they felt merited further analysis. They chose to examine transcripts for evidence of faculty members' perceptions of the following: (1) the characteristics of successful tertiary STEM students, (2) the desirable knowledge base of successful tertiary STEM students, and (3) reasons why students are not always successful in university STEM courses. The three aforementioned authors independently coded each of the transcripts, making a list of categories-supported by evidence from the transcript-under each theme (e.g., specific characteristics of successful tertiary STEM students) while, at the same time, looking for evidence of themes that had not been initially considered. No additional themes manifested during this analysis. Discussion of the codes led to the grouping of themes 1 and 
2 named above, because faculty did not distinguish between the characteristics and desirable knowledge base of successful tertiary STEM students in their responses to interview questions. Over multiple meetings, the same authors met to discuss their combined categories under each theme group. During those meetings, they developed common language to describe the categories, coming to consensus on each category description. At this point, they used the category descriptions to code the interview transcripts, making note of the number of responses that corresponded to each category. As a final level of analysis, they developed two theme-based assertions describing faculty perceptions of (1) the characteristics of successful tertiary STEM students and (2) the major obstacle that keeps tertiary STEM students from being successful. In the sections that follow, we provide supporting evidence for each of these assertions. All faculty members are referred to using assigned pseudonyms.

\section{Results}

\section{Assertion 1}

Faculty identified a number of characteristics of successful students in STEM courses and programs. The majority of the identified characteristics were not discipline-specific, but more general and applicable across disciplines.

As previously mentioned, university STEM faculty function as some of the "experts at the end" of many STEM educational pathways. Through their interactions with the students in their programs, faculty members become aware of the characteristics, skills, and knowledge base of their successful students. As researchers who are interested in promoting STEM education and in encouraging more students to enter STEM-related fields and careers, we wanted to know the characteristics of successful tertiary STEM students in order to develop programs and curricula that would cultivate these same characteristics in students who were progressing through their primary and secondary education.

Each of the 27 faculty members we interviewed perceived general traits and skills-like curiosity and problem solving skills-as being important characteristics of successful tertiary STEM students. Only six faculty members perceived discipline-specific knowledge and skills-like understanding the functions of the organelles in a eukaryotic cell-as being critical to the success of STEM students. In fact, five of the faculty we interviewed indicated that they could help students develop the more discipline-specific skills, characteristics, and understandings as long as the students possessed certain general skills and characteristics-skills that are applicable across STEM disciplines.

The skills and characteristics of successful STEM students that faculty described fell into three broad categories. Overall, faculty members asserted that personality traits such as curiosity, inquisitiveness, and a strong work ethic are important for successful STEM students. Most faculty also agreed that successful students have key academic skills, like the ability to synthesize information, good written and oral communication skills, and good problem-solving abilities. Finally, faculty in this study described successful STEM students' affective qualities: that they have positive attitudes toward STEM fields and practices and, more importantly, that they are keenly interested and engaged in finding STEM in the world around them.

Personality traits of successful tertiary STEM students. Certain personality traits were seen as being important contributors to the success of tertiary STEM students. Across disciplines, a majority of faculty (20 of the 27 interviewed) perceived that successful tertiary STEM students tend to be innately curious about and interested in their field of study. Faculty believed that curiosity is a trait that is especially valued in science because it fosters engagement.

What I want is a curious human-being, who doesn't take anything for granted, who comes and I teach her or him something and she immediately questions, starts questioning, "Why? You told me that you want me to remember this or learn this. Why?” (Dr. Scott, Engineering) 
Faculty felt that curiosity and inquisitiveness are important driving forces for student learning in STEM disciplines. Faculty in this study perceived that inquisitive students are more interested in STEM content and more attentive about the concepts being discussed in their courses than students who do not have an inquisitive nature. Dr. Singh (Biology) suggested that inquisitiveness reflects students' thirst for knowledge and helps them excel in challenging STEM disciplines. When we asked him to describe the characteristics of successful STEM students, he said:

They're inquisitive. They're asking questions, of everything, all the time; and they're never satisfied with the answers they get. Not that they're dismissing the answers, but they want to know more. And, it's not that they're just asking the questions and then giving up, it's that they're asking and then going and finding the information. And I think in today's world that's even easier for students to do because they can hop on their iPad or their iPhone.

Finally, and equally pertinent for faculty members, was the work ethic that students carry into their classroom and research practices. According to eleven faculty members, students who are willing to work will succeed in STEM courses and programs. Moreover, STEM faculty perceive that they are more able to help-and interested in helping-students who are willing to work than students who are not willing to work. Dr. Newman (Engineering), for example, indicated that a strong work ethic was essential to success in an engineering program: "They have to want to work. I can do wonders with that."

Academic skills of successful tertiary STEM students. Twenty-two of the faculty members interviewed named key skills that students who succeed in their fields possess. The most frequently-cited skill was the ability to independently solve problems. Nine faculty members felt this skill was important. Seven faculty members named the ability to synthesize information as key to student success. Six faculty members thought that a student's ability to communicate was important. For example, Dr. Singh (Biology) explained that successful students in his field are able to take information from different sources and synthesize it into a coherent whole:

They've taken their curiosity and they've translated that to, essentially, a scholarly level, where they're engaged in trying to, not just understand the world, but to, to define new ways to understand the world. I think that actually is the transition that a student goes through, sometime between the end of their sophomore year and graduating, is that they go from learning facts to synthesizing answers.

Many faculty members also identified strong written and oral communication skills as being essential for success in STEM-related fields and careers and, thus, for success in tertiary STEM courses and programs. Dr. McGuire (Engineering), for example, said that successful students have "an ability to communicate their ideas, to express themselves in writing and orally." Despite communication being an important skill, many faculty members in this study worried that students do not start their tertiary education with this skill.

Good synthesis and communication skills were not seen as sufficient for success in tertiary STEM fields, however. Of all the academic skills that faculty identified in their successful students, the one that seemed to be most important was a willingness and an ability to independently identify and solve problems. When we asked Dr. Peyton (Geoscience) to identify the characteristics of his successful students, he said that they are better at "identifying that there's a problem and then...picking at it from different directions." Dr. Peyton elaborated, saying that it was important for students to be willing and able to solve problems independently: "Willingness to do-solve their own problems. [...] A willingness to simply attack a problem and find out whatever information you need in order to actually do it." Many faculty agreed with Dr. Peyton's assessment, stating that 
their successful students tend to be eager to solve problems without being given all the information or steps to do so. This is not to say that students must be able to correctly solve all problems on their own; however, they must demonstrate a willingness to try. Most faculty we interviewed were willing to help students make additional progress once the students had invested time and effort into solving problems on their own.

Affective characteristics of successful tertiary STEM students. Affective factors such as attitude and engagement have received serious attention in the field as indicators of achievement in science and mathematics (Singh, Granville, \& Dika, 2002). Three faculty members said that students who are engaged in the community and in their field are more likely to succeed in STEM. Two faculty members described a positive attitude about work and learning as important to STEM success.

In fact, nine faculty perceived that students with an interest in STEM concepts are easier to teach and have an easier time learning and progressing in STEM courses and programs. They stated that they can help any student who is interested and who has a willingness to work to learn STEM concepts. Dr. Delgado (Computer Science) stated "If you come, and you're interested, and you want to work for it, we'll teach it to you." Dr. Rogers (Physics) also emphasized the importance of students having a desire to learn:

They have to have the desire to learn. [...] I tell this to my own students, "I'm creating conditions for you to learn, but I can't force you to learn." You can take the horse to water, but you can't force him to drink.

While faculty perceived and described several traits and skills that contribute to students' success in STEM disciplines, they also identified a number of factors that they perceived as being barriers to students' success. By far, the most common theme among the barriers faculty members described was the novice student's relationship with mathematics. Interviewees' discussion of this factor is described in greater detail in the following section.

\section{Assertion 2}

All faculty perceived mathematics as being the major obstacle to students' success in tertiary STEM courses and programs.

All of the faculty interviewed in the current study identified a lack of mathematical knowledge and skills as being the major roadblock to student success in tertiary STEM courses and majors. Faculty from all disciplines represented in this survey, including the life sciences-which might be considered less reliant upon math as a foundation-agreed that deficiencies in math are barriers to STEM success, particularly in introductory courses. Dr. Shears (Allied Health Sciences) summarized the perceptions of the faculty when she said that, "students in the undergraduate class, generally, are not prepared for my class. They're lacking quantitative mathematics skills." Dr. Hart (Life Sciences) concurred: “The vast majority of students that come to any university in the country are under-prepared in math-and especially in the sciences. I think that we need to work on math skills early and often."

Lack of mathematical knowledge and skill was seen as particularly problematic because, as Dr. McGuire (Engineering) noted, students "need the math skills [...] to be able to understand the coursework that they're going to embark on." Dr. Rogers (Physics) concurred: "The biggest problem with students in the introductory courses is that they just don't have the mathematical sophistication that they need. Math is our language, so the biggest challenge is getting them to overcome their fear of math." The faculty perceived that when students do not enter tertiary STEM courses and programs with sufficient mathematical knowledge, a lot of class time that should have been dedicated to discipline-specific content was focused, instead on "how to solve math problems." Dr. Parikh (Physics) described this phenomenon: 
What happens is we'll start talking about physics, and people will get lost in the math; and then I have to stop and say, "Let's back up, and let me explain this in a way that we don't need to worry too much about the math, or we don't have to do all the algebra to rearrange equations." And that's where things get held up in the class.

Mathematics faculty also agreed that students enter college with insufficient math skills-or with a fear of math-that keeps them from succeeding in tertiary math coursework and programs specifically. Dr. Mico (Mathematics) stated that he has seen a decrease in the mathematical skills of incoming students since he joined the faculty 25 years ago. When we asked him if he felt like students were prepared for his classes, he said no, claiming that "what is killing them is the [lack of] algebra background." Additionally, he said that "the kids, they cannot tackle word problems. The minute they see a word problem, they get chickened out, and the same thing with the algebra." Dr. Palmer, another mathematics professor, claimed that, although students might have previously learned some desirable mathematical skills before entering college, they do not seem aware of when and where it is appropriate to apply those skills.

They're lacking connections. They don't know what to use and when. They misuse a skill in a place where they shouldn't be using it, and then they neglect to use it in places they should. That probably comes from a lack of depth, I guess.

It is clear that, to the faculty interviewed in this study, lack of mathematical knowledge and skills was seen as the major obstacle to success in tertiary STEM courses. But what type and level of mathematical knowledge and skills do faculty perceive to be desirable in an incoming tertiary STEM student? The answers to this question differed by individual faculty members and, in some cases, by discipline; however, there were some common themes in the faculty responses. In the sections that follow, we discuss those general themes.

Math skills tertiary STEM students should have to be successful. During their interviews, faculty discussed both the minimum level of mathematical prowess that they expected in their incoming undergraduates as well as mathematical skills that they perceived to be vital but currently lacking in undergraduate students.

Although faculty in engineering and physics declared that it would be useful for students to have some calculus-or at least pre-calculus-knowledge before entering tertiary STEM programs and courses, all of the faculty members we interviewed agreed that, at a minimum, entering students should have strong algebraic skills. Algebra is a common prerequisite to many undergraduate STEM courses and an area in which students in STEM-related programs are expected to be proficient. When asked which mathematical skills he expects in his incoming students, Dr. Clark (Mathematics) stated:

The skills would be fluency in the algebra. If I do something on the board, some calculus stuff, and then quickly do the algebra, that quickly doing the algebra shouldn't lose them. If I skip some algebra, they should be comfortable doing that.

The key feature of Dr. Clark's statement, which was expressed by many faculty, was that students not only need to have received basic training in algebraic skills, but that they must be "fluent" in those skills. We will discuss this topic further in a section that follows; but, essentially_and according to the faculty we interviewed-being "fluent" in mathematical skills means being comfortable with using those skills, being able to quickly apply those skills, and knowing when it is appropriate to apply those skills. 
A particular application of algebra that two faculty participants perceived as lacking in their current undergraduate students is the ability to interpret word problems and convert them into mathematical language and equations. Dr. Rios (Chemistry), for example, commented that many students who are capable of manipulating algebraic equations find converting word problems into mathematical equations challenging:

[The problem] isn't so much the math that's covered, which is pretty basic algebra, but it's being able to look at a description of some sort of a chemical problem and convert that into a math equation that they can solve. That's the biggest place where they struggle. I think that if I were to simply give them the math problem that you have to solve to be able to solve this chemistry problem, most of them could probably do it, but once you have a sentence you need to convert into an equation, that's probably the biggest roadblock for them.

Mathematics coursework and background tertiary STEM students should have to be successful. In order to develop a comfort level and fluency with algebraic skills, faculty participants said that students should take as many math courses as possible before entering college. A major point of consensus among faculty was that all incoming students should complete math coursework that would allow them to take calculus courses during their first semester in college. "At the very minimum I would expect that the students entering here would've had a solid foundation in pre-calculus, so that they would be ready for calculus" (Dr. Rogers, Physics).

The underlying implication that faculty conveyed is that taking more math courses before entering college gives aspiring STEM students exposure and practice with mathematical skills, which then-at least ideally-leads to the development of the comfort level and "fluency" that they see as desirable and essential for their successful tertiary STEM students. Although simply taking math courses does not guarantee that students will develop the desired fluency in mathematical skills, faculty did note that those who tend to do better in their university STEM courses are those who have taken a lot of math courses during their secondary education. For example, Dr. Rios (Chemistry) agreed with other faculty that students should take at least a pre-calculus course before entering college. However, he expected that students who had taken calculus courses during high school would be more likely to succeed in his courses than students who had only taken pre-calculus courses:

I would say that they should have taken at least pre-calculus, but I think that students that have enrolled in a calculus course are probably likely to do better [in my courses]. I'm not sure if that's because students that are further along in math will have an easier time with chemistry in general or if it's because the additional math experience has helped them more.

While faculty did not know if additional mathematics coursework would increase students' mathematical knowledge or their fluency with mathematics, they all agreed that prospective students should take as many math courses as they could before entering a STEM major or course of study. Dr. Rogers (Physics) said that this is a viewpoint he promotes to prospective tertiary STEM students whenever he visits secondary classrooms:

When I visit high schools and middle schools, [...] they'll ask me, "What does it take to become a physicist, or scientist?" And the first thing I'll say is, "you've got to stick with the math. You've got to be comfortable with the math. You've got to work with it. It's a language; it's how we communicate. You can't do science without the math, and that's any science, even biology."

Beyond skills and coursework: The mathematical "fluency" of successful tertiary STEM students. As previously noted, although all faculty believed that students should take as many math courses as they can before they enter college, faculty did not believe that simply attending courses was sufficient to prepare students for 
university STEM majors and courses. It was more important that students develop a sort of comfort level and fluency with mathematical concepts and skills. Three faculty members mentioned that students who had taken fewer mathematics courses in high school but who happened to be very comfortable with approaching math problems were able to learn STEM content better than students who had taken extensive coursework, a point made by Dr. Palmer (Mathematics): "I honestly can tell you it's not the coursework [that makes a student successful]. It's the level of attention paid to the details of that coursework." He continued by saying that successful students are "more practiced [in their mathematical skills]; they're more at ease. They know what to apply when, usually quicker, without a reminder, context cue."

Several faculty participants ( 5 out of 27) expressed a concern that students are not able to develop a comfort level or fluency with math because they have a fear of math. They also stated a belief that students have been told that math is difficult, which may deter them from finding math approachable. They perceived that many students develop an aversion to math at an early age, which then impedes their ability to positively approach math and the STEM topics that depend on mathematical knowledge and skill.

Faculty discussed how the fear of math has become a major obstacle to STEM students' success. Dr. Rogers (Physics) discussed how fear of mathematics can become a roadblock for students, particularly in the introductory courses:

The biggest problem with students in the introductory courses is that they just don't have the mathematical sophistication that they need. Math is our language, so the biggest challenge is getting them to overcome their fear of math. The physics, per se, is not that challenging, once they can see it on a conceptual basis, because, I always tell them, "you're doing physics every morning of your existence. I'm just trying to make you aware of it." Whether it's using your auditory ears to detect sound waves or light waves, it's all physics. Math, the fear of math, I think is the biggest problem for me.

Dr. Parikh (Allied Health Sciences) shared similar sentiments about students in his program who do not understand why they need math to understand the concepts in their field of study:

Math is the root of a lot of what we do; and, unfortunately, a lot of people have this math phobia. Students have a hard time making a connection between why they need to understand trigonometry [in a kinesiology course]. [...] It does make teaching biomechanics a little bit more challenging when they don't have the math and the physics background.

Students' fear of math has been discussed as one of the major obstacles for recruiting students into STEM-related fields (Krantz, 1999; Perry, 2004). Many students prefer to avoid math classes and even majors that require quantitative skills (Bisk, 2013). Dr. Peyton (Geoscience) said that, in order for students to succeed in his courses, they should not be afraid of math. However, he also noted that his students tend to lose interest as soon as he connects course content to math, even if that math is fairly simple.

Not being afraid of math is pretty important. Not that we do crazy math on any sort of regular basis; but to not be afraid of putting together a pretty serious calculation, that seems to be a key. Usually I have five students who are interested in what I'm doing, and then they see that you have to use computers and a little bit of math. That usually turns them off. Then they usually don't continue [in the program].

Overall, it is clear that faculty believe that lack of fluency with mathematical skills is the major obstacle that students must overcome to be successful in tertiary STEM courses and programs. Given this finding, it is import- 
ant that future research examine in more detail what it means to be "fluent" in mathematical—and particularly in algebraic-skills and how such fluency can be developed.

\section{Discussion}

Faculty provide an important perspective into issues related to tertiary STEM recruitment and retention because they are experts who have successfully navigated the STEM educational pipeline. As such, they understand some of the characteristics of people who have been successful in STEM educational pathways and fields. Additionally, as instructors, they are in a position of positively impacting the recruitment and retention of tertiary STEM students.

The results described here provide key insights into faculty perceptions of (1) the characteristics of successful STEM students and (2) the major barrier to students' success in STEM courses and programs of study. Faculty members' perceptions of student characteristics related to success in STEM fields fall into two categories. First are skills that they perceive as malleable, that may be fostered, promoted, and developed-skills like problem-solving ability, mathematics ability, and the ability to communicate effectively via written and oral means. A second group of characteristics are those that faculty perceive to be innate to the student, over which faculty members perceive they have limited influence-characteristics like curiosity, inquisitiveness, work ethic, positive attitude, and a sense of engagement. Given the influence faculty beliefs have on their classroom practices and the influence of classroom practices on STEM recruitment and retention, it is important to individually consider the potential implications of both categories of perceived characteristics of successful tertiary STEM students.

First, faculty identified characteristics that they perceive can be developed in STEM students. These characteristics generally aligned with the research literature (e.g., mathematics ability is related to success in STEM fields; see Astin \& Astin, 1992); however, when we asked faculty how they thought students should develop these characteristics, the faculty mentioned that students should take particular classes in high school or participate in clubs like the chess club (to develop problem-solving abilities) or a toastmasters club (to develop oral communications skills). What we found interesting is that faculty did not mention ways that they could structure their classroom experiences in order to help students develop these desirable characteristics. Instead, faculty stated that students should develop these characteristics outside of the classroom. Faculty often have very little training in pedagogy or learning theories (Brown et al., 2006; Mansour, 2009; Sunal et al., 2001). As a result, although they may wish to help their students develop these desirable characteristics, they may not know which instructional strategies they can use to do so (e.g., the use of ill-structured problems in classes can help students develop problem-solving abilities; see King \& Kitchener, 1994). They may also have misconceptions that would prevent them from implementing such effective strategies in their classrooms. For example, faculty might not believe their students are capable of using active learning strategies or effectively participating in group work (Johnson \& Hall, 2007). Alternatively, they might believe that they cannot use active learning strategies in large classrooms or that they cannot cover the required course material if they devote class time to the types of active learning strategies that are known to promote desirable characteristics (Brown et al., 2006; Fang, 1996; Mansour, 2009).

Second, faculty identified what they perceive to be "innate" characteristics of successful tertiary STEM students. These characteristics also generally correlate with the research literature. For example, research indicates that students who are interested in and curious about STEM concepts are more likely to be successful in STEM fields (see Astin \& Astin, 1992; Sullins et al., 1995). Faculty perceptions of the origins of these characteristics will impact their classroom practices. If faculty believe they cannot influence a student's sense of engagement in the classroom or their level of persistence because these characteristics are "innate", they will be less likely to change their classroom practices in ways that will support the development of these desirable characteristics, even though research indicates that certain classroom practices-like contextualizing course material in real-world events-can positively influence students' level of persistence in STEM fields (Maltese \& Tai, 2011). 
It should be reiterated that, while faculty perceptions of the characteristics of successful STEM students generally align with the research literature, faculty did not mention experiences or instructional strategies they could implement in their classrooms to help students develop these characteristics. A future study could examine faculty members' perceptions of the experiences and strategies that can be used to develop desirable characteristics in their tertiary STEM students. A comparison of the faculty members' perceptions with the factors that have been shown in the research literature to support STEM recruitment and retention could then inform the design of professional development opportunities to help faculty (1) align their understanding with the current research on what makes students successful in STEM disciplines, (2) implement instructional strategies that will develop desirable characteristics in their tertiary STEM students, and (3) identify and address ways to overcome potential barriers to the implementation these instructional strategies.

\section{Limitations of the Current Study}

There are two main characteristics of the participant population for the current study that may limit the study's results. First, all of the university STEM faculty interviewed for the current project are employed at the same university. It is reasonable to assume that these faculty work with similar students and, thus, have similar experiences with and perceptions of the students. Those perceptions, however, may be different than the perceptions of faculty at other-or different types of-institutions. Future studies could build on the results of the current study by examining the perceptions of university STEM faculty at multiple institutions and at multiple institution types (i.e., research-intensive, primarily undergraduate, 2-year college, etc.). Second, although all STEM faculty at the university were invited to participate in the current study, participation was voluntary. As such, the study population (1) is not representative of the numbers of faculty in different STEM disciplines on campus and (2) does not include many faculty from particular STEM disciplines. For example, only 2 biology faculty members agreed to participate in the current study even though the biology department is one of the largest STEM departments at this particular university. It may be that faculty perceptions of the characteristics of successful tertiary STEM students differ by discipline. The small numbers of participants from particular disciplinary backgrounds did not allow us to examine this possibility in the current study; however, an expanded future study could compare the perceptions of university STEM faculty from different disciplines (for example, physics faculty perceptions of successful tertiary STEM students could be compared with the perceptions of health sciences faculty). Despite these limitations, the current study is useful in that it provides initial insight into the perceptions of university STEM faculty about the characteristics of their successful students, insight which can be used as the foundation for future studies.

\section{Conclusions}

Although much of what has been mentioned may require future study and exploration, it is clear that STEM faculty members are in a unique position to influence whether or not students persevere in STEM disciplines. As experts, faculty have successfully navigated the STEM educational pipeline and understand some of the characteristics of people who have been successful in STEM educational pathways and fields. As instructors, they are in a position to positively impact the recruitment and retention of tertiary STEM students. As mentors, faculty model STEM related skills and behaviors and provide valuable points of entry into the fields. Ultimately, steps must be taken to ensure that faculty is aware of ways to facilitate positive experiences for students in their courses, as well as understand what factors have positive impacts on student success in STEM courses and programs of study. The current study provides initial steps in that direction.

\section{Acknowledgements}

Preparation of this article was supported by a grant from the Nevada State GEAR UP Program. 


\section{References}

Ashby, C. (2006). Science, technology, engineering, and mathematics: Trends and the role of federal programs. Testimony before the Committee on Education and the Workforce, House of Representatives. Retrieved from

http://republicans.edlabor.house.gov/archive/hearings/109th/fc/competitiveness05006/ashby.htm.

Astin, A. W., \& Astin, H. S. (1992). Undergraduate science education: The impact of different college environments on the educational pipeline in the sciences. Los Angeles, CA: University of California, Graduate School of Education, Higher Education Research Institute.

Betz, N. E., \& Hackett, G. (1983). The relationship of mathematics self-efficacy expectations to the selection of science-based college majors. Journal of Vocational Behavior, 23, 329-345.

Bisk, R. (2013). Improving math success in higher education. New England Journal of Higher $3 / 13 / 2013,1$.

Education,

Bounous-Hammarth, M. (2000). Pathways to success: Affirming opportunities for science, mathematics, and engineering majors. Journal of Negro Education, 69, 92-111.

Brown, P. L., Abell, S. K., Demir, A., \& Schmidt, F. (2006). College science teachers' views of classroom inquiry. Science Education, 90, 784-802.

Chang, M., Sharkness, J., Newman, C., \& Hurtado, S. (2014). What matters in college for retaining aspiring scientists and engineers from underrepresented racial groups. Journal of Research in Science Teaching, $51,555-580$.

Commission on Professionals in Science and Technology [CPST]. (2007). Is US science and technology adrift? STEM Workforce Data Project: Report No. 8. Washington, DC: CPST.

Fang, Z. (1996). A review of research on teacher beliefs and practices. Educational Research, 38, 47-65.

Hall, C., Dickerson, J., Batts, D., Kauffman, P., \& Bosse, M. (2011). Are we missing opportunities to encourage interest in STEM fields? Journal of Technology Education, 23.

Johnson, M. J., \& Hall, J. L. (2007). Impact of one science teacher's beliefs on his instructional practice. Journal of Education and Human Development, 1.

Kember, D. (1997). A reconceptualisation of the research into university academics' conceptions of teaching. Learning and Instruction, 7, 255-275.

King, P. M., \& Kitchener, K. S. (1994). Developing reflective judgment: Understanding and promoting intellectual growth and critical thinking in adolescents and adults. San Francisco: Jossey-Bass.

Krantz, S. G. (1999). How to teach mathematics. Providence: American Mathematical Society.

Kuh, G. D., \& Hu, S. (2001). The effects of student-faculty interaction in the 1990s. The Review of Higher Education, 24, 309-332.

Laplante, B. (1997). Teachers' beliefs and instructional strategies in science: Pushing analysis further. Science Education, 81, 277-294.

Lichtenstein, G., Loshbaugh, H. G., Claar, B., Bailey, T. L., \& Sheppard, S. (2007). Should I stay or should I go? Engineering students' persistence is based on little experience or data. Proceedings of the American Society for Engineering Education Annual Conference, Honolulu, Hawaii.

Lowell, B. L., \& Regets, M. (2006). A half-century snapshot of the STEM workforce, 1950-2000. Washington, D.C.: Commission on Professionals in Science and Technology.

Maltese, A. V., \& Tai, R. H. (2011). Pipeline persistence: Examining the association of educational experiences with earned degrees in STEM among U.S. students. Science Education, 95, 877-907.

Mansour, N. (2009). Science teachers' beliefs and practices: Issues, implications and research agenda. International Journal of Environmental \& Science Education, 4, 25-48. 
Marton, F. (1986). Phenomenography-A research approach to investigating different understandings of reality. Journal of Thought, 21, 28-49.

Nespor, J. (1987). The role of beliefs in the practice of teaching. Journal of Curriculum Studies, 19, 317-328.

Newman, C. (2011). Engineering success: The role of faculty relationships with African American undergraduates. Journal of Women and Minorities in Science and Engineering, 17, 193-207.

Orgill, M. (2007). Phenomenography. In G. M. Bodner \& M. Orgill (Eds.), Theoretical frameworks for research in chemistry/science education (pp. 132-151). Upper Saddle River, NJ: Pearson Education Publishing.

Pajares, M. F. (1992). Teachers' beliefs and educational research: Cleaning up a messy construct. Review of Educational Research, 62, 307-332.

Perry, A. (2004). Decreasing math anxiety in college students. College Student Journal, 38, 321-334.

President's Council of Advisors on Science and Technology [PCAST]. (2012). Engage to excel: Producing one million additional college graduate with degrees in Science, Technology, Engineering and Mathematics. Retrieved November 16, 2013 from http://www.whitehouse.gov/.

Rask, K. (2010). Attrition in STEM fields at a liberal arts college: The importance of grades and pre-collegiate preferences. Economics of Education Review, 29, 892-900.

Seymour, E., \& Hewitt, N. (1994). Talking about leaving: Factors contributing to high attrition rates among science, mathematics, and engineering undergraduate majors. Boulder, CO: Bureau of Sociological Research, University of Colorado.

Singh, K., Granville, M., \& Dika, S. (2002). Mathematics and science achievement: Effects of motivation, interests, and academic engagement. The Journal of Education Research, 95, 323-323.

State of the Union Address. (2012). Retrieved March 10, 2013, from https://www.whitehouse.gov/state-of-theunion-2012.

Sullins, E. S., Hernandez, D., Fuller, C., \& Tashiro, J. S. (1995). Predicting who will major in a science discipline: Expectancy-value theory as part of an ecological model for studying academic communities. Journal of Research in Science Teaching, 32, 99-119.

Sunal, D. W., Hodges, J., Sunal, C. S., Whitaker, K. W., Freeman, L. M., Edwards, L., Johnston, R. A., \& Odell, M. (2001). Teaching science in higher education: faculty professional development and barriers to change. School Science and Mathematics, 101, 246-257.

Terenzini, P. T., Rendon, L. I., Upcraft, M. L., Millar, S. B., Allison, K. W., Gregg, P. L., et al. (1994). The transition to college: Diverse students, diverse stories. Research in Higher Education, 35(1), 57-73.

Thiry, H., Laursen, S. L., \& Hunter, A.-B. (2011). What experiences help students become scientists? A comparative study of research and other sources of personal and professional gains for STEM undergraduates. The Journal of Higher Education, 82, 357-388.

Tobias, S. (1990). They're not dumb, they're different: Stalking the second tier. Tucson, AZ: Research Corporation.

Venville, G., Rennie, L., Hanbury, C., \& Longnecker, N. (2013). Scientists reflect on why they chose to study science. Research in Science Education, 43, 2207-2233.

Walden, S. E., \& Foor, C. (2008). "What's to keep you from dropping out?" Student immigration into and within engineering. Journal of Engineering Education, 97, 191-205

Wang, X. (2013). Why students choose STEM majors: Motivation, high school learning, and postsecondary context of support. American Educational Research Journal, 50, 1081-1121.

Watkins, J., \& Mazur, E. (2013). Retaining students in Science, Technology, Engineering, and Mathematics (STEM) majors. Journal of College Science Teaching, 42, 36-43. 